\title{
Control of the neurovascular coupling by nitric oxide-dependent regulation of astrocytic $\mathrm{Ca}^{2+}$ signaling
}

\section{Manuel F. Muñoz, Mariela Puebla and Xavier F. Figueroa*}

Facultad de Ciencias Biológicas, Departamento de Fisiología, Pontificia Universidad Católica de Chile, Santiago, Chile

\section{Edited by:}

Luc Leybaert, Ghent University, Belgium

\section{Reviewed by:}

Erlend Arnulf Nagelhus, University of Oslo, Norway

Ping Liu, University of Connecticut Health Center, USA

\section{*Correspondence:}

Xavier F. Figueroa, Facultad de Ciencias Biológicas, Departamento de Fisiología, Pontificia Universidad Católica de Chile, Portugal 49, Santiago 8331010, Chile e-mail:xfigueroa@bio.puc.cl
Neuronal activity must be tightly coordinated with blood flow to keep proper brain function, which is achieved by a mechanism known as neurovascular coupling. Then, an increase in synaptic activity leads to a dilation of local parenchymal arterioles that matches the enhanced metabolic demand. Neurovascular coupling is orchestrated by astrocytes. These glial cells are located between neurons and the microvasculature, with the astrocytic endfeet ensheathing the vessels, which allows fine intercellular communication. The neurotransmitters released during neuronal activity reach astrocytic receptors and trigger a $\mathrm{Ca}^{2+}$ signaling that propagates to the endfeet, activating the release of vasoactive factors and arteriolar dilation. The astrocyte $\mathrm{Ca}^{2+}$ signaling is coordinated by gap junction channels and hemichannels formed by connexins ( $\mathrm{C} \times 43$ and $\mathrm{C} \times 30$ ) and channels formed by pannexins (Panx-1). The neuronal activity-initiated $\mathrm{Ca}^{2+}$ waves are propagated among neighboring astrocytes directly via gap junctions or through ATP release via connexin hemichannels or pannexin channels. In addition, $\mathrm{Ca}^{2+}$ entry via connexin hemichannels or pannexin channels may participate in the regulation of the astrocyte signaling-mediated neurovascular coupling. Interestingly, nitric oxide (NO) can activate connexin hemichannel by S-nitrosylation and the $\mathrm{Ca}^{2+}$-dependent $\mathrm{NO}$-synthesizing enzymes endothelial NO synthase (eNOS) and neuronal NOS (nNOS) are expressed in astrocytes. Therefore, the astrocytic $\mathrm{Ca}^{2+}$ signaling triggered in neurovascular coupling may activate NO production, which, in turn, may lead to $\mathrm{Ca}^{2+}$ influx through hemichannel activation. Furthermore, NO release from the hemichannels located at astrocytic endfeet may contribute to the vasodilation of parenchymal arterioles. In this review, we discuss the mechanisms involved in the regulation of the astrocytic $\mathrm{Ca}^{2+}$ signaling that mediates neurovascular coupling, with a special emphasis in the possible participation of $\mathrm{NO}$ in this process.

Keywords: cerebral arterioles, cerebral blood flow, connexins, pannexins, gap junctions, endothelial nitric oxide synthase, neuronal nitric oxide synthase, TRPV4 channels

\section{INTRODUCTION}

Information processing by the neuronal network in the central nervous system (CNS) is a very complex task that relies on dynamic interactions between neurons and glial cells, but also on functional association among brain cells and cerebral microcirculation, which is intended to be reflected by the concept "neurovascular unit" (Koehler et al., 2006; Abbott et al., 2010; Muoio et al., 2014). The coordination of neuronal and vascular function is essential to maintain cerebral activity because the nervous tissue has a very high metabolic rate that depends on the appropriate blood supply (Rolfe and Brown, 1997). Then, changes in neuronal activity must be paralleled by proportional and timely variations in blood flow to thereby match the metabolic demand. This is achieved by a communication mechanism that links neuronal and vascular function, which is known as neurovascular coupling (Iadecola, 2004; Hawkins and Davis, 2005; Leybaert, 2005; Koehler et al., 2006). In this context, an increment in synaptic activity rapidly leads to vasodilation of local parenchymal arterioles and, consequently, to an increase in blood-borne energy substrate that satisfies the enhanced metabolic demand (Anderson and Nedergaard, 2003; Iadecola, 2004; Leybaert, 2005).

Although neurovascular coupling may be simply explained by the release of vasoactive signals from neurons, this signaling process is much more complex and astrocytes have emerged as central players in the communication of the changes in synaptic activity to local parenchymal arterioles (Anderson and Nedergaard, 2003; Koehler et al., 2006; Filosa and Iddings, 2013). Astrocytes are multifunctional cells that play a critical role in the maintenance of cerebral homeostasis and are in a strategic position to mediate and coordinate neurovascular coupling, since they are located between neurons and the microvasculature (Anderson and Nedergaard, 2003; Zonta et al., 2003a; Koehler et al., 2006; Filosa and Iddings, 2013; Figure 1). In this context, astrocytes project processes that surround neuronal synapses and express functional receptors for several neurotransmitters, 


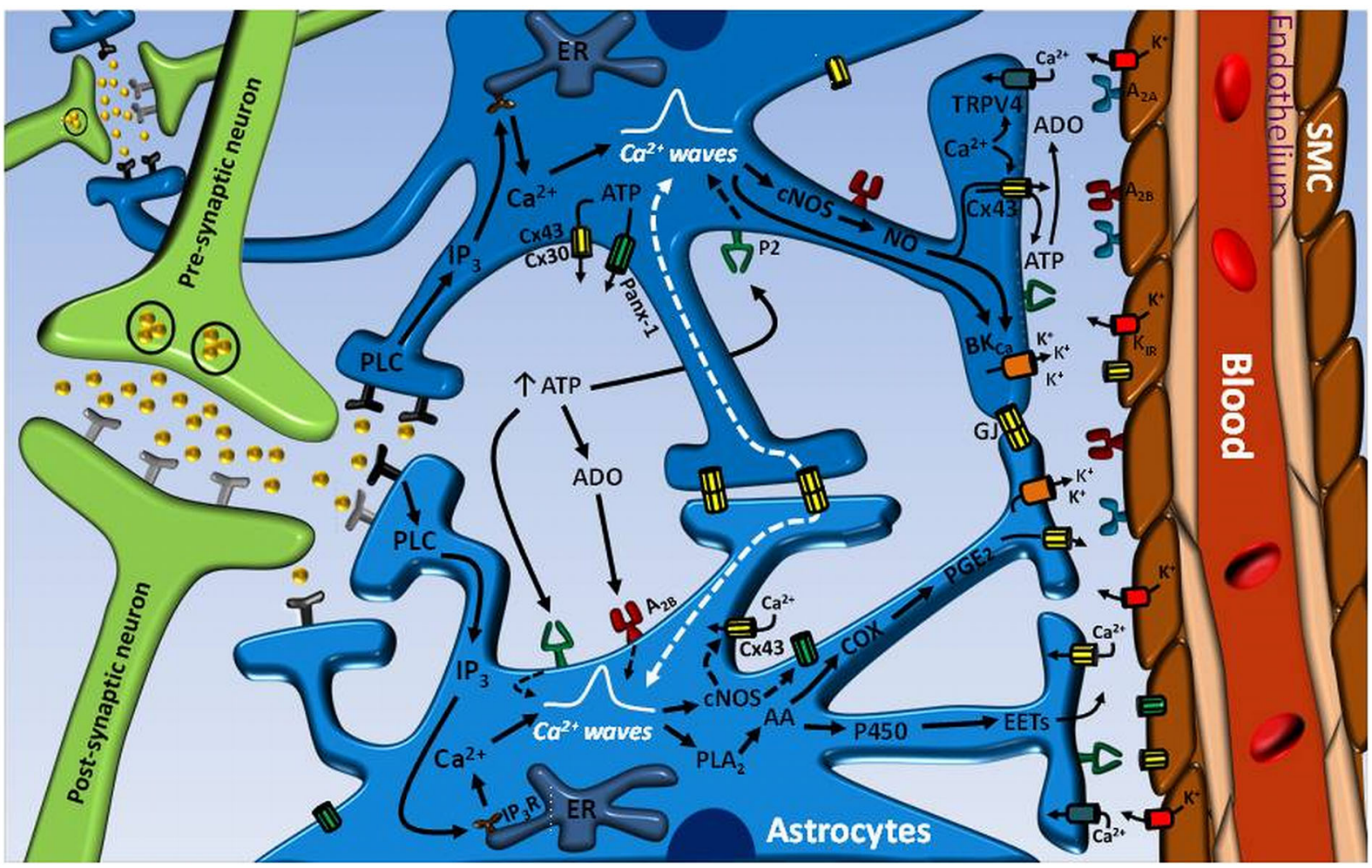

FIGURE 1 | Astrocyte-mediated signaling mechanisms involved in the control of neurovascular coupling. Neurotransmitters released during an increase in neuronal activity can exit the synaptic cleft and activate receptors on astrocyte processes. The stimulation of astrocyte receptors initiates an inositol 1, 4, 5-triphosphate $\left(\mathrm{IP}_{3}\right)$ receptor $\left(\mathrm{IP}_{3} \mathrm{R}\right)$-mediated $\mathrm{Ca}^{2+}$ signal that is propagated through the astrocytic processes into the endfeet and activates the phospholipase $A_{2}\left(P L A_{2}\right)$-arachidonic acid (AA) pathway and large conductance $\mathrm{Ca}^{2+}$-activated $\mathrm{K}^{+}$channels $\left(\mathrm{BK}_{\mathrm{Ca}}\right)$. In turn, the activation $\mathrm{PLA}_{2}-\mathrm{AA}$ pathway leads to cytochrome P450 epoxygenase (P450)-mediated epoxyeicosatrienoic acids (EETs) production and cyclooxygenase

(COX)-dependent prostaglandin $\mathrm{E}_{2}\left(\mathrm{PGE}_{2}\right)$ formation. Consequently, EETs and $\mathrm{PGE}_{2}$ release and $\mathrm{BK}_{\mathrm{Ca}}$ channel opening evoke the vasodilation of parenchymal arterioles. The astrocyte-mediated vasodilator signal may be coordinated by the propagation of an inter-astrocyte $\mathrm{Ca}^{2+}$ signal via ATP release-mediated purinergic receptor $\left(P_{2}\right)$ stimulation or directly by gap junction communication (GJ). ATP may be released by either $\mathrm{C} \times 30$ - or Cx43-based hemichannels or pannexin-1 (Panx-1)-formed channels. The hydrolysis of ATP to adenosine (ADO) by ecto-ATPases may also contribute to enhance and coordinate the $\mathrm{Ca}^{2+}$ signal through $\mathrm{A}_{2 \mathrm{~B}}$ receptor activation on astrocytes. ADO formation from $\mathrm{C} \times 43$ hemichannel-driven ATP release at the endfeet may participate in the vasodilator response by the stimulation of $A_{2 A}$ receptors on vascular smooth muscle cells (SMC) of parenchymal arterioles. The astrocytic $\mathrm{Ca}^{2+}$ signal may also activates nitric oxide (NO) production by both $\mathrm{Ca}^{2+}$-dependent constitutive NO synthases (cNOS), eNOS and nNOS, which may play an important role in the regulation of neurovascular coupling by the activation of $\mathrm{C} \times 43$ hemichannels and $\mathrm{BK}_{\mathrm{Ca}}$ channels. It is noteworthy that $\mathrm{C} \times 43$ hemichannel opening may contribute to the $\mathrm{Ca}^{2+}$ signal by providing a pathway for $\mathrm{Ca}^{2+}$ influx and, in addition, may participate in the astrocytic vasodilator mechanisms by allowing the efficient release of $\mathrm{PGE}_{2}$ and $\mathrm{NO}$. which provides to these cells with a fine mechanism to sense neuronal activity (Porter and McCarthy, 1997; Zonta et al., 2003a; Koehler et al., 2006; Takano et al., 2006). Additionally, the astrocytic endfeet of the same astrocytes are found in an intimate, tight spatial organization with parenchymal vessels, where the endfeed reach to close proximity of the microvasculature and encase the vessel wall (Figure 1), which allows a fine and efficient communication between astrocytes and vascular cells (Anderson and Nedergaard, 2003; Iadecola, 2004; Koehler et al., 2006). This cellular spatial organization determines the basic signaling substrate for regulation of neurovascular coupling in which stimulation of receptors located at astrocyte processes by neurotransmitters released during an increase in neuronal activity initiates a $\mathrm{Ca}^{2+}$ signal that propagates through the astrocytic processes into the endfeet (Zonta et al., 2003a; Filosa et al., 2004; Koehler et al., 2006; Straub et al., 2006; Straub and
Nelson, 2007). The generation of an astrocytic endfoot $\mathrm{Ca}^{2+}$ signal leads to the release of vasoactive factors that, in turn, evoke the arteriolar dilation required to produce an increase in local blood flow proportional to the increment in synaptic activity (Zonta et al., 2003a; Koehler et al., 2006; Takano et al., 2006; Straub and Nelson, 2007). Consistent with the astrocytic $\mathrm{Ca}^{2+}$ signaling-dependent control of arteriolar vasomotor tone, the increase in astrocytic endfoot cytosolic $\mathrm{Ca}^{2+}$ concentration $\left(\left[\mathrm{Ca}^{2+}\right]_{\mathrm{i}}\right)$ precedes vasodilation of cerebral arterioles (Straub et al., 2006; Straub and Nelson, 2007; Filosa and Iddings, 2013).

Several $\mathrm{Ca}^{2+}$-dependent vasodilator mechanisms have been proposed to be activated at the astrocytic endfeet facing the arteriolar vessel wall. The most recognized vasodilator signals released from astrocytic endfeet are epoxyeicosatrienoic acid (EETs) and prostaglandin $\mathrm{E}_{2}\left(\mathrm{PGE}_{2}\right)$, which are synthesized 
by the cytochrome P450 epoxygenase and by a cyclooxygenase enzyme-dependent pathway, respectively (Figure 1), from the initial $\mathrm{Ca}^{2+}$-dependent arachidonic acid formation (Anderson and Nedergaard, 2003; Zonta et al., 2003a,b; Koehler et al., 2006; Straub and Nelson, 2007). Nevertheless, it must be noted that the release of arachidonic acid by astrocytes has been shown to lead to vasoconstriction through the production of 20-hydroxyeicosatetraenoic acid (20-HETE) in the arteriolar smooth muscle cells (Mulligan and MacVicar, 2004; Metea and Newman, 2006). This apparent controversy in the vascular response triggered by astrocytic $\mathrm{Ca}^{2+}$ signals (vasodilation vs. vasoconstriction) has been addressed in further studies. Girouard et al. (2010) show in mouse cortical brain slices that changes in the concentration of $\mathrm{K}^{+}$ions in the space found between astrocytic endfoot and vessel wall may control the arteriolar vasomotor tone in a bimodal manner (i.e., generating vasodilation or vasoconstriction). Astrocytic endfeet express $\mathrm{Ca}^{2+}$-activated $\mathrm{K}^{+}$ channels of large conductance $\left(\mathrm{BK}_{\mathrm{Ca}}\right)$ and vascular smooth muscle cells of the parenchymal arterioles express inward rectifier $\mathrm{K}^{+}$channels $\left(\mathrm{K}_{\mathrm{ir}}\right)$ (Price et al., 2002; Filosa et al., 2006; Girouard et al., 2010). Then, the increase in $\left[\mathrm{Ca}^{2+}\right]_{\mathrm{i}}$ generated in the endfeet during the neurovascular coupling triggers the opening of $\mathrm{BK}_{\mathrm{Ca}}$, which leads to the release of $\mathrm{K}^{+}$ion into the perivascular space, producing an increase in the local extracellular $\mathrm{K}^{+}$ concentration proportional to the magnitude of the $\mathrm{Ca}^{2+}$ signal that triggers the $\mathrm{BK}_{\mathrm{Ca}}$ activation. Thereby, an increase in the perivascular $\mathrm{K}^{+}$concentration smaller than $20 \mathrm{mM}$ activates the $\mathrm{K}_{\text {ir }}$ channels located in the smooth muscle cell membrane facing the endfeet (Filosa et al., 2006; Girouard et al., 2010; Figure 1), leading to smooth muscle hyperpolarization, and consequently, vasodilation (Girouard et al., 2010). However, higher increases in extracellular $\mathrm{K}^{+}$concentration $(>20 \mathrm{mM})$ eliminates the electrochemical gradient of $\mathrm{K}^{+}$and produces smooth muscle cell depolarization and vasoconstriction (Girouard et al., 2010). In addition, the direction of the vasomotor response initiated by the astrocytic endfoot $\mathrm{Ca}^{2+}$ signal has also been proposed to depend on the metabolic state of the tissue, which was evaluated by changing the oxygen tension in the superfusion solution of the experimental preparation. In this context, when hippocampal-neocortical slices were superfused with an artificial cerebrospinal fluid equilibrated with $95 \% \mathrm{O}_{2}$, the response associated to the increase in astrocytic $\mathrm{Ca}^{2+}$ was vasoconstriction, but, in contrast, a vasodilation was activated in the presence of $20 \% \mathrm{O}_{2}$ (Gordon et al., 2008; Attwell et al., 2010).

\section{ASTROCYTIC $\mathrm{Ca}^{2+}$ SIGNALING IN NEUROVASCULAR COUPLING}

The activation of $\mathrm{Ca}^{2+}$ oscillations is a central signaling mechanism for astrocyte function and for transducing neuronal activity into vasodilation of parenchymal arterioles (Zonta et al., 2003a; Filosa et al., 2004; Straub et al., 2006; Straub and Nelson, 2007; Filosa and Iddings, 2013). The most relevant neuronal signal that triggers an increase in $\left[\mathrm{Ca}^{2+}\right]_{\mathrm{i}}$ in neurovascular coupling is the activation of metabotropic glutamate receptors located on astrocyte projections associated with glutamatergic synapses (Zonta et al., 2003a; Straub and Nelson, 2007; Filosa and Iddings, 2013). However, it should be noted that other neurotransmitters such as ACh, ATP and GABA or the release of neuropeptides such as somatostatine and vasoactive intestinal peptide from interneurons can also evoke the initiation of a $\mathrm{Ca}^{2+}$ signal in astrocytes (Stout et al., 2002; Li et al., 2003; Koehler et al., 2006; Straub et al., 2006). The synaptic activitydependent activation of an astrocytic $\left[\mathrm{Ca}^{2+}\right]_{i}$ is propagated as a $\mathrm{Ca}^{2+}$ wave along the perisynaptic astrocytic processes through the astrocyte to finally reach the perivascular endfeet (Zonta et al., 2003a; Filosa et al., 2004; Straub et al., 2006). The, apparently, most important and well-described mechanism involved in this $\mathrm{Ca}^{2+}$ signal is the activation of a phospholipase C (PLC)dependent pathway, with the consequent generation of inositol 1, 4, 5-triphosphate $\left(\mathrm{IP}_{3}\right)$ from membrane phospholipids, and then, the stimulation of $\mathrm{Ca}^{2+}$ release from the endoplasmic reticulum (ER) via $\mathrm{IP}_{3}$ receptors $\left(\mathrm{IP}_{3} \mathrm{R}\right.$; Parri and Crunelli, 2003; Straub et al., 2006; Straub and Nelson, 2007; Filosa and Iddings, 2013; Figure 1). However, PLC signaling also leads to diacylglycerol formation and protein kinase C (PKC) activation, which may also be involved in the modulation of $\mathrm{Ca}^{2+}$ oscillations as a negative feedback mechanism, since inhibition of PKC results in spontaneous $\left[\mathrm{Ca}^{2+}\right]_{i}$ increases in slices of ventrobasal thalamus in resting conditions (Parri and Crunelli, 2003). Although $\mathrm{Ca}^{2+}$ release via ryanodine receptors was shown to contribute to the generation of astrocytic $\mathrm{Ca}^{2+}$ signals in cultured astrocytes (Golovina and Blaustein, 1997, 2000), the inhibition or activation of these receptors using ryanodine or caffeine, respectively, did not affect the characteristics of endfoot $\mathrm{Ca}^{2+}$ signals observed in native astrocytes in cortical slices (Straub et al., 2006).

Consistent with the participation of $\mathrm{IP}_{3} \mathrm{R}$ in the propagation of $\left[\mathrm{Ca}^{2+}\right]_{\mathrm{i}}$ increases into the astrocytic endfeet, spatially restricted photorelease of $\mathrm{IP}_{3}$ from caged $\mathrm{IP}_{3}$ within endfeet initiates a $\mathrm{Ca}^{2+}$ signal with similar characteristics to those observed in response to neuronal activation by electric field stimulation (Straub et al., 2006). Furthermore, the astrocytic endfoot $\left[\mathrm{Ca}^{2+}\right]_{\mathrm{i}}$ increase observed in both cases, $\mathrm{IP}_{3}$ uncaging and neuronal activation, was markedly blunted after the intracellular $\mathrm{Ca}^{2+}$ stores were depleted using cyclopiazonic acid (CPA), a blocker of the sarcoplasmic/ER $\mathrm{Ca}^{2+}$ ATPase (SERCA; Straub et al., 2006). Interestingly, $\mathrm{Ca}^{2+}$ signals initiated by photorelease of $\mathrm{IP}_{3}$ did not spread back to the cell body, but, as expected, this increase in $\left[\mathrm{Ca}^{2+}\right]_{i}$ was associated with the initiation of a vasodilator response in the adjacent arteriole, suggesting that each endfoot works as a vasodilator unit in which the regenerative $\mathrm{Ca}^{2+}$ signaling machinery is spatially organized to direct the propagation of the $\mathrm{Ca}^{2+}$ oscillations in function of the activation of the $\mathrm{Ca}^{2+}$-dependent vasoactive signaling (Straub et al., 2006; Straub and Nelson, 2007). In addition, the intensity of the $\mathrm{IP}_{3} \mathrm{R}$-generated $\mathrm{Ca}^{2+}$ signals associated to neuronal activation were heterogeneous throughout of the processes and endfeet, with spatially restricted regions of elevated $\left[\mathrm{Ca}^{2+}\right]_{\mathrm{i}}$ (Straub et al., 2006), which indicate that the generation of $\mathrm{Ca}^{2+}$ signals is a dynamic process with specialized points of amplification along the perivascular projections that may be associated with the activation of vasodilator signaling pathways during neurovascular coupling. Although these data confirm that $\mathrm{IP}_{3} \mathrm{Rs}$ play a central role in the generation and propagation 
of $\mathrm{Ca}^{2+}$ oscillations, it is important to note; however, that inhibition of $\mathrm{IP}_{3} \mathrm{Rs}$ with xestospongin only attenuates the $\mathrm{Ca}^{2+}$ signals generated in response to neuronal activation by electrical field stimulation in brain slices (Straub et al., 2006), and then, an additional mechanism may be involved in the response.

In addition to $\mathrm{IP}_{3} \mathrm{R}$, astrocytic endfeet also express plasma membrane cation channels of the transient receptor potential vanilloid (TRPV) family (Nilius and Voets, 2005; Pedersen et al., 2005), specifically, the TRPV4 subtype (Benfenati et al., 2007) and Dunn et al. (2013) recently showed that stimulation of these channels with the agonist GSK1016790A increases the amplitude and frequency of spontaneous $\mathrm{Ca}^{2+}$ oscillations observed in cortical astrocytic endfeet of mouse coronal brain slices, which was associated with vasodilation of parenchymal arterioles. As expected, this response was absent in the presence of the TRPV4 antagonist HC-067047 or in TRPV4 knockout mice (Dunn et al., 2013). As $\mathrm{IP}_{3} \mathrm{R}$ in the ER membranes are activated by $\mathrm{Ca}^{2+}$, it is thought that propagation of $\mathrm{Ca}^{2+}$ waves is supported by a mechanism of $\mathrm{Ca}^{2+}$-induced $\mathrm{Ca}^{2+}$ release via $\mathrm{IP}_{3} \mathrm{Rs}$ in the ER membranes (Li et al., 2003; Parri and Crunelli, 2003; Straub et al., 2006), which seems to be enhanced through $\mathrm{Ca}^{2+}$ entry via TRPV4 channels (Dunn et al., 2013). Consistent with this notion, treatment with CPA reduced the amplitude, frequency and propagation distance of the GSK1016790A-induced endfoot $\mathrm{Ca}^{2+}$ oscillations observed in brain slices. The participation of $\mathrm{IP}_{3} \mathrm{Rs}$ in the effect of CPA was confirmed using xestospongin (Dunn et al., 2013). In addition, inhibition of TRPV4 channels with HC-067047 resulted in a reduction of the rise in endfoot $\left[\mathrm{Ca}^{2+}\right]_{i}$ and the dilation of the associated parenchymal arteriole evoked by electrical field stimulation of brain slices from wild type animals, but not from TRPV4 knockout mice (Dunn et al., 2013). Interestingly, these results were confirmed in the intact animal through the evaluation of the cerebral hemodynamic response in vivo by measuring cerebral blood flow in the mouse somatosensory cortex using laser Doppler flowmetry in a cranial window. Although TRPV4 inhibition did not alter resting cerebral vascular function in this model, the evaluation of neurovascular coupling resulted in a reduction in the increase in cerebral blood flow observed in response to contralateral whisker stimulation (Dunn et al., 2013). These results indicate that TRPV4 channels are involved in the fine regulation of neurovascular coupling likely by interacting with the $\mathrm{IP}_{3} \mathrm{R}$-mediated $\mathrm{Ca}^{2+}$ signals in the astrocyte endfeet.

\section{CONNEXINS AND PANNEXINS IN NEUROVASCULAR COUPLING}

An individual astrocyte connects multiple neuronal synapses with surrounding vessels and, conversely, an increase in neuronal activity is sensed by many astrocytes. Then, a single astrocyte must integrate the information of several neurons, but, in turn, the astrocyte-mediated neurovascular signaling must be coordinated between all astrocytes involved in the response to efficiently translate enhanced synaptic activity into higher blood flow to the whole brain region in which increased the metabolism (Araque et al., 1999; Haydon and Carmignoto, 2006). This tight and precise coordination of the astrocyte
$\mathrm{Ca}^{2+}$ signaling generated by neuronal activation seems to be achieved, in great part, through connexin (Cxs)-mediated intercellular communication (Simard et al., 2003; Orellana et al., 2011).

Connexins belong to the protein family that forms the intercellular channels known as gap junctions, which communicate directly the cytoplasm of two neighboring cells, allowing intercellular transfer of current and solutes smaller than $1.4 \mathrm{~nm}$ of diameter (Perkins et al., 1998; Unger et al., 1999), such as ions and second messengers (e.g., $\mathrm{Ca}^{2+}$ and $\mathrm{IP}_{3}$ ) (Evans and Martin, 2002; Saez et al., 2003; Isakson et al., 2007). The association of six connexins makes up a hemichannel (i.e., half of gap junction channel) and head to head alignment of two hemichannels, each one provided by each adjacent cell, composes a gap junction channel (Saez et al., 2003). In addition to form gap junction channels, individual hemichannels are functional and provide a communication pathway between the intra and extracellular compartments, allowing influx of ions or release of paracrine/autocrine signals (Bruzzone et al., 2001; Stout et al., 2002; Goodenough and Paul, 2003; Cherian et al., 2005; Figueroa et al., 2013).

It has been described that astrocytes express several connexin isoforms, but $\mathrm{Cx} 30$ and $\mathrm{Cx} 43$ have been recognized as the most prominent connexins of these cells (Thompson and MacVicar, 2008; Ezan et al., 2012; Gaete et al., 2014). Although gap junctions provide a direct communication pathway for the propagation and coordination of $\mathrm{Ca}^{2+}$ signals between astrocytes (Simard et al., 2003; Orellana et al., 2011; Chandrasekhar and Bera, 2012), connexin hemichannels may also be involved in this process. Opening of $\mathrm{Cx} 43$-formed hemichannels is control by $\mathrm{Ca}^{2+}$ and these hemichannels are permeable to $\mathrm{Ca}^{2+}$ (De Bock et al., 2011, 2012; Chandrasekhar and Bera, 2012). Then, hemichannels may contribute to generate $\mathrm{Ca}^{2+}$ signals initiated by $\left[\mathrm{Ca}^{2+}\right]_{\mathrm{i}}$ increases as those observed in astrocytes in response to neuronal activation. In this context, $\mathrm{Ca}^{2+}$ oscillations activated by bradykinin in rat brain endothelial (RBE4) cells or MadinDarby canine kidney (MDCK) cells were sensitive to shorttime application $(<30 \mathrm{~min})$ of the connexin blocking peptides ${ }^{37,43}$ Gap27 (a mimetic peptide of the second extracellular loop of $\mathrm{Cx} 37$ and $\mathrm{Cx} 43$ ) or ${ }^{43} \mathrm{Gap} 26$ (a mimetic peptide of the first extracellular loop of $\mathrm{Cx} 43$ ), respectively (De Bock et al., 2011, 2012). This rapid effect of connexin mimetic peptides is consistent with hemichannel inhibition, because gap junction function is only disrupted by longer periods of treatment. In addition, in MDCK cells, bradykinin-induced $\mathrm{Ca}^{2+}$ oscillations were also inhibited after reducing the extracellular $\mathrm{Ca}^{2+}$ concentration, siRNA silencing of $\mathrm{Cx} 43$ or altering the carboxy-terminal-dependent $\mathrm{Ca}^{2+}$-mediated regulation of $\mathrm{Cx} 43$ hemichannels by loading the cells with the peptide CT9 that correspond to the last 9 amino acids of the Cx43 carboxyterminal (De Bock et al., 2012). As $\mathrm{Ca}^{2+}$ oscillations depend on $\mathrm{IP}_{3} \mathrm{R}$ activation and hemichannel opening by photolytic release of $\mathrm{Ca}^{2+}$ did not triggered $\mathrm{Ca}^{2+}$ oscillations (De Bock et al., 2012); these results show that $\mathrm{Cx} 43$-formed hemichannels may contribute to the generation of $\mathrm{IP}_{3} \mathrm{R}$ commanded $\mathrm{Ca}^{2+}$ signals, probably, by providing a pathway for $\mathrm{Ca}^{2+}$ stores refilling. 
In addition, hemichannels formed by $\mathrm{Cx} 30$ and $\mathrm{Cx} 43$ have been described to be permeable to ATP (Stout et al., 2002; Kang et al., 2008; Sipos et al., 2009; Svenningsen et al., 2013) and ATP release has been shown to represent an important mechanism involved in the regenerative propagation of $\mathrm{Ca}^{2+}$ signals along the astrocyte processes and in the coordination of this signal between neighboring astrocytes (Stout et al., 2002; Orellana et al., 2011). Likewise Cx43 hemichannels, Cx30-based hemichannels may also be activated by $\mathrm{Ca}^{2+}$, and then, the increase in astrocytic $\left[\mathrm{Ca}^{2+}\right]_{\mathrm{i}}$ can lead to ATP release through Cx30 hemichannels or Cx43 hemichannels or both (Figure 1). The subsequent rise in extracellular ATP concentration can stimulate P2 purinergic receptors on either the same astrocyte from which it was released or on neighboring astrocytes (Simard et al., 2003; Suadicani et al., 2009; Orellana et al., 2011), which may contribute to enhance the $\mathrm{Ca}^{2+}$ wave propagation or to the intercellular coordination of the $\mathrm{Ca}^{2+}$ signaling, respectively. In addition of ATP release, the importance of connexins in neurovascular coupling is highlighted by the fact that $\mathrm{Cx} 43$ hemichannels were also found to mediate the release of $\mathrm{PGE}_{2}$ (Cherian et al., 2005; Figure 1).

It is noteworthy that astrocytes express pannexin-1 (Panx-1), a member of a protein family (Panx-1, Panx-2 and Panx-3) that forms channels with similar characteristics of connexin hemichannels (Panchin et al., 2000; Bruzzone et al., 2003). Panx1 -formed channels are not thought to contribute to gap junctionlike communication, but they have been found to mediate ATP release in astrocytes (Iglesias et al., 2009; Orellana et al., 2011; Suadicani et al., 2012). Although there is an increasing body of evidence supporting the release of ATP via connexin hemichannels and pannexin channels, it is important to note that astrocytes may also release ATP by $\mathrm{Ca}^{2+}$-dependent exocytosis (Pryazhnikov and Khiroug, 2008). The relevance of ATP release in neurovascular coupling and the involvement of connexins, pannexins and exocytosis have not yet conclusively determined, but it is likely that, if these three mechanisms co-exist, they contribute to different phases of the response or are activated in distinct physiological conditions, which may provide fine regulation of ATP signaling in astrocytes.

Astrocytes and cerebral arterioles express adenosine receptors (Pilitsis and Kimelberg, 1998; Ngai et al., 2001) and ATP may rapidly be hydrolyzed to adenosine by extracellular ecto-ATPases (Xu and Pelligrino, 2007; Pelligrino et al., 2011; Vetri et al., 2011), which, in astrocytes, have been described to be located close to hemichannels (Joseph et al., 2003; Fields and Burnstock, 2006). Then, the ATP hydrolysis to adenosine may also contribute to the propagation and coordination of astrocyte-mediated $\mathrm{Ca}^{2+}$ signals and directly to the dilation of parenchymal arterioles in response to neuronal activation (Figure 1). Interestingly, activation of $A_{2 B}$ receptors has been reported to elicit an increase in $\left[\mathrm{Ca}^{2+}\right]_{i}$ (Pilitsis and Kimelberg, 1998) and potentiate the ATP-induced $\mathrm{Ca}^{2+}$ response in astrocytes (Jiménez et al., 1999; Alloisio et al., 2004). Consistent with the participation of these receptors in neurovascular coupling, $A_{2 B}$ antagonists inhibit the increase in cerebral blood flow observed in response to whisker stimulation (Shi et al., 2008). In addition, adenosine derived from ATP released via connexin hemichannels located at astrocyte endfeet
(Simard et al., 2003) may evoke arteriolar dilation by direct stimulation of vascular smooth muscle $A_{2 A}$ or $A_{2 B}$ receptors (Ngai et al., 2001), which is coherent with the inhibition by $A_{2 A}$ antagonists of the pial arteriolar dilation observed during sciatic nerve stimulation (Meno et al., 2001).

\section{NITRIC OXIDE (NO) IN NEUROVASCULAR COUPLING}

Nitric oxide (NO) is a widely distributed, pleiotropic signaling molecule synthesized by the enzyme NO synthase (NOS) from the amino acid L-arginine (Moncada et al., 1991). Three isoforms of NOS have been described: endothelial NOS (eNOS), neuronal NOS (nNOS) and inducible NOS (iNOS; Moncada et al., 1991; Alderton et al., 2001). eNOS and nNOS are expressed constitutively primarily, but not exclusively, in endothelial cells and neurons, respectively, and the activation of these isoforms depends on an increase in $\left[\mathrm{Ca}^{2+}\right]_{\mathrm{i}}$ (Alderton et al., 2001). In contrast, the expression of iNOS is typically assumed to be induced by cytokines and others agents during the immune response and its activity does not depend on an increment in $\left[\mathrm{Ca}^{2+}\right]_{\mathrm{i}}$ (Pautz et al., 2010). NO is a potent vasodilator (Moncada et al., 1991), which led to the proposal that neurovascular coupling is directly mediated by the $\mathrm{Ca}^{2+}$-dependent $\mathrm{NO}$ production associated to the activation of cortical neurons. In fact, inhibition of $\mathrm{NO}$ production with $\mathrm{N}^{\mathrm{G}}$-nitro-L-arginine (L-NA, a general NOS inhibitor), deletion of nNOS and specific nNOS inhibition with 7-nitroindazole have been reported to attenuate the increase in sensory cortex cerebral blood flow observed in response to vibratory hindpaw stimulation in mouse (Kitaura et al., 2007) or transcallosal electrical stimulation in vivo in rat (Brožíčková and Otáhal, 2013). Although these data support the participation of nNOS in neurovascular coupling, they are not in disagreement with the critical role played by astrocytes in this response, because NO-synthesizing enzymes are not present in excitatory neurons of many brain regions (Iwase et al., 1998; Karagiannis et al., 2009; Tricoire et al., 2010) and astrocytes have been shown to express eNOS and nNOS (Gabbott and Bacon, 1996; Doyle and Slater, 1997; Shin, 2001; Lin et al., 2007). Additionally, astrocytes may also express low levels of iNOS, which has also been related with normal astrocyte function (Buskila et al., 2007). NO production by astrocytes has been proposed to participate in the regulation of neuronal activity (Buskila et al., 2007), astrocytic spontaneous $\mathrm{Ca}^{2+}$ transients (Schipke et al., 2008) and the astrocytic release of glutamate and ATP (Bal-Price et al., 2002; Ida et al., 2008).

It is well-known that the effects of NO are mediated by the activation of the soluble guanylate cyclase and the cGMP/PKG pathway, which has been considered as the "classical" mechanism of NO signaling (Moncada et al., 1991). Nevertheless, beside activation of soluble guanylate cyclase, S-nitrosylation (also termed as S-nitrosation) has emerged as an important "nonclassical" mechanism of NO signaling (Ahern et al., 2002; Martínez-Ruiz et al., 2013). It is important to note that, in contrast to the activation of the cGMP/PKG pathway, the S-nitrosylation signaling mechanism is preferentially observed close to the NO source, where NO concentration is higher (Martínez-Ruiz et al., 2013). S-nitrosylation comprises NOmediated oxidation of cysteine residues to form a nitrosothiol, 
a post-translational modification that has been recognized to modulate the activity of several signaling proteins (Martínez-Ruiz et al., 2013). As a physiological signaling process, S-nitrosylation is transient and the nitroso group can be removed (i.e., denitrosylation) after the stimulation fades out (Martínez-Ruiz et al., 2013; Sengupta and Holmgren, 2013). Interestingly, connexin function is regulated by S-nitrosylation (Retamal et al., 2006). In astrocytes, Cx43 was found to be S-nitrosylated in response to metabolic inhibition, which was tightly related to opening of hemichannels formed by this connexin isoform (Retamal et al., 2006). This finding is coherent with the recent demonstration that NO opens hemichannels expressed in cultured astrocytes and in HeLa cells transfected with Cx37, Cx40 or Cx43 (Figueroa et al., 2013), which shows that, in addition of $\mathrm{Cx} 43$ hemichannels, $\mathrm{NO}$ also induces the activation of Cx37- and Cx40-based hemichannels. Interestingly, this work also demonstrated that $\mathrm{NO}$ crosses the plasma membrane preferentially through connexin hemichannels (Figueroa et al., 2013), at least, through those formed by Cx37, Cx40 or Cx43. On the other hand, the effect of NO on Panx-1-formed channels is controversial, since NO has been found to activate or inhibit these channels and in both cases S-nitrosylation was proposed to be involved (Zhang et al., 2008; Lohman et al., 2012).

The potential relevance of $\mathrm{NO}$-induced connexin hemichannel activation in neurovascular coupling is highlighted by the contribution of $\mathrm{NO}$ to the ATP-elicited $\mathrm{Ca}^{2+}$ signal in astrocytes that described $\mathrm{Li}$ and collaborators ( $\mathrm{Li}$ et al., 2003). These authors found that the release of $\mathrm{Ca}^{2+}$ from the intracellular stores initiated by ATP leads to the activation of a NOdependent pathway of $\mathrm{Ca}^{2+}$ influx that plays an important role in the increase in $\left[\mathrm{Ca}^{2+}\right]_{i}$ and the subsequent $\mathrm{Ca}^{2+}$ store refilling observed in this response. The NO-induced $\mathrm{Ca}^{2+}$ influx did not depend on the activation of cGMP production ( $\mathrm{Li}$ et al., 2003), suggesting the involvement of S-nitrosylation. Interestingly, the $\mathrm{Ca}^{2+}$ influx activated by $\mathrm{NO}$ was sensitive to $\mathrm{Cd}^{2+}$ and 2-aminoethoxydiphenyl borate (2-APB; Li et al., 2003). Although $\mathrm{Cd}^{2+}$ is thought to be a nonselective $\mathrm{Ca}^{2+}$ channel blocker and 2-APB is recognized as an $\mathrm{IP}_{3} \mathrm{R}$ antagonist, both blockers have been shown to inhibit connexin hemichannels (Tao and Harris, 2007; Tang et al., 2009). Then, these results suggest that $\mathrm{NO}$-dependent connexin hemichannel activation by S-nitrosylation may be involved, not only in ATP release, but also in the $\mathrm{Ca}^{2+}$ signaling evoked by ATP in astrocytes, and consequently, in the $\mathrm{Ca}^{2+}$ wave propagation observed in the neurovascular coupling (Figure 1), which is consistent with the recent report indicating that inhibition or deletion of eNOS blunted the astrocyte-mediated neurovascular couplingdependent vasodilation (Stobart et al., 2013). Furthermore, as connexin hemichannels mediate the intercellular transfer of NO (Figueroa et al., 2013) and Cx43 is preferentially expressed in astrocytic endfeet (Simard et al., 2003), Cx43-formed hemichannels may contribute to the neuronal activation-induced vasodilation by directing the NO signaling toward parechymal arterioles (Figure 1). In addition of connexins, NO signaling has also been shown to be involved in the control of TRPV4 and $\mathrm{BK}$ channel function. NO regulates negatively TRPV4 channels by S-nitrosylation (Lee et al., 2011) and induces the opening of BK directly by S-nitrosylation or through the cGMP/PKG pathway (Bolotina et al., 1994; Tanaka et al., 2000), which suggests that $\mathrm{NO}$ may regulate the astrocytic $\mathrm{Ca}^{2+}$ signaling at different levels and contribute to the BK-mediated vasodilation (Figure 1).

Although opening and regulation of connexin hemichannels is not yet clear in the context of astrocyte function in normal physiological conditions, these data suggest that $\mathrm{Ca}^{2+}$. mediated activation of $\mathrm{NO}$ production may be involved in the regulation of the astrocytic $\mathrm{Ca}^{2+}$ signal triggered in neurovascular coupling through activation of a $\mathrm{Ca}^{2+}$ influx or ATP release via $\mathrm{Cx} 43$-formed hemichannels. However, the involvement of connexin hemichannels or Panx-1 channels in the NO-dependent regulation of the neuronal activationinitiated $\mathrm{Ca}^{2+}$ and ATP signaling in astrocytes remains to be determined.

\section{CONCLUDING REMARKS}

Neurovascular coupling is a complex signaling mechanism that depends on functional and coordinated interactions of astrocyte with neurons and vascular cells. Changes in neuronal activity are transduced into vasomotor responses through astrocytic $\mathrm{Ca}^{2+}$ signals, which are activated by the neurotransmitters released at the synapsis, principally glutamate. The $\mathrm{Ca}^{2+}$ signal is propagated through the astrocytic processes to the endfeet by an $\mathrm{IP}_{3} \mathrm{R}$-dependent $\mathrm{Ca}^{2+}$-induced $\mathrm{Ca}^{2+}$ release mechanism and by autocrine ATP signaling via P2 purinergic receptors or $\mathrm{A}_{2 \mathrm{~B}}$ adenosine receptors (after ATP hydrolysis by ecto-ATPases). ATP may be released through hemichannels formed by Cx30 or $\mathrm{Cx} 43$ and/or channels formed by Panx-1 and, in addition, activation of these channels provides a direct pathway for $\mathrm{Ca}^{2+}$ influx that may be involved in the regulation of the $\mathrm{IP}_{3} \mathrm{R}$ initiated astrocytic $\mathrm{Ca}^{2+}$ signal. However, although connexins and Panx-1 are likely to play a central role in the astrocytemediated neurovascular coupling, NO seems to control and orchestrate the development of the $\mathrm{Ca}^{2+}$ response, since $\mathrm{NO}$ production is activated by the initial $\mathrm{IP}_{3} \mathrm{R}$-mediated $\mathrm{Ca}^{2+}$ release and $\mathrm{NO}$ is involved in the generation, propagation and regulation of the $\mathrm{Ca}^{2+}$ signaling. This is because the increase in NO concentration leads to ATP release and activates a $\mathrm{Ca}^{2+}$ influx pathway that contributes to the astrocytic $\mathrm{Ca}^{2+}$ signal observed in response to both ATP or metabotropic glutamate receptor stimulation. The NO-evoked $\mathrm{Ca}^{2+}$ influx seems to be also involved in the regulation of the $\mathrm{Ca}^{2+}$ signaling by contributing to refill the $\mathrm{IP}_{3} \mathrm{R}$-associated intracellular $\mathrm{Ca}^{2+}$ store. Although the activation of $\mathrm{Cx} 43$ hemichannels by $\mathrm{S}$-nitrosylation may provide the pathway for the NO-dependent ATP release and $\mathrm{Ca}^{2+}$ influx, the participation of connexin- or Panx-1 formed channels in the NO-dependent $\mathrm{Ca}^{2+}$ signals must be confirmed in future investigations.

The propagation of the neuronal-activated $\mathrm{Ca}^{2+}$ wave into the astrocyte endfeet is supported and regulated by specialized signaling mechanisms of these subcellular domains. Astrocyte endfeet express $\mathrm{Cx} 43$ hemichannels and TRPV4 channels and although the generation of the $\mathrm{Ca}^{2+}$ signal in the endfeet is governed by $\mathrm{IP}_{3} \mathrm{Rs}, \mathrm{Ca}^{2+}$-dependent activation of $\mathrm{Cx} 43$ 
hemichannels and TRPV4 channels may contribute to enhance the $\mathrm{Ca}^{2+}$ signal at specialized microdomains associated with the activation of vasodilator mechanisms. Interestingly, diffusion or production of $\mathrm{NO}$ in the endfeet may be involved in the control of the $\mathrm{Ca}^{2+}$ signal by inducing the opening of Cx43 hemichannels and the inhibition of TRPV4 channels. Furthermore, the NO-mediated $\mathrm{Cx} 43$ hemichannel activation may also play an important role in the astrocyte endfootelicited vasodilation by providing the pathway for the release of $\mathrm{NO}$ and $\mathrm{PGE}_{2}$ into the perivascular space. In addition of Cx43 hemichannels, NO may also induce the activation of BK channels at the astrocytic enfeet, which highlights the relevance of the interaction between $\mathrm{NO}$ and $\mathrm{Ca}^{2+}$ in the regulation of the astrocyte-dependent vasodilator signals activated during neurovascular coupling. The specific contribution of eNOS and nNOS to the astrocyte-conducted $\mathrm{Ca}^{2+}$-mediated vasodilator signaling may be determined by the subcellular location and spatial organization of these NOS isoforms in relation to other signaling proteins involved in the regulation of neurovascular coupling. Then, the study of the subcellular distribution of eNOS and nNOS in astrocytes and the possible association of these NO-synthesizing enzymes with connexins, Panx-1, TRPV4 channels and BK channels may be an interesting and fruitful area of investigation that may help to understand the complex and dynamic regulation of neurovascular coupling.

\section{ACKNOWLEDGMENTS}

This work was supported by Grant Puente 30/2014 from Vicerrectoría de Investigación y Doctorado_-VRI de la Pontificia Universidad Católica de Chile and Grant Anillos ACT-140091 from the Comisión Nacional de Investigación Científica y Tecnológica-CONICYT.

\section{REFERENCES}

Abbott, N. J., Patabendige, A. A., Dolman, D. E., Yusof, S. R., and Begley, D. J. (2010). Structure and function of the blood-brain barrier. Neurobiol. Dis. 37, 13-25. doi: 10.1016/j.nbd.2009.07.030

Ahern, G. P., Klyachko, V. A., and Jackson, M. B. (2002). cGMP and S-nitrosylation: two routes for modulation of neuronal excitability by NO. Trends Neurosci. 25, 510-517. doi: 10.1016/s0166-2236(02)02254-3

Alderton, W. K., Cooper, C. E., and Knowles, R. G. (2001). Nitric oxide synthases: structure, function and inhibition. Biochem. J. 357, 593-615. doi: 10.1042/02646021:3570593

Alloisio, S., Cugnoli, C., Ferroni, S., and Nobile, M. (2004). Differential modulation of ATP-induced calcium signalling by $\mathrm{A} 1$ and $\mathrm{A} 2$ adenosine receptors in cultured cortical astrocytes. Br. J. Pharmacol. 141, 935-942. doi: 10.1038/sj.bjp.0705707

Anderson, C. M., and Nedergaard, M. (2003). Astrocyte-mediated control of cerebral microcirculation. Trends Neurosci. 26, 340-344; author reply 344-345. doi: 10.1016/s0166-2236(03)00142-5

Araque, A., Parpura, V., Sanzgiri, R. P., and Haydon, P. G. (1999). Tripartite synapses: glia, the unacknowledged partner. Trends Neurosci. 22, 208-215. doi: 10.1016/s0166-2236(98)01349-6

Attwell, D., Buchan, A. M., Charpak, S., Lauritzen, M., Macvicar, B. A., and Newman, E. A. (2010). Glial and neuronal control of brain blood flow. Nature 468, 232-243. doi: 10.1038/nature09613

Bal-Price, A., Moneer, Z., and Brown, G. C. (2002). Nitric oxide induces rapid, calcium-dependent release of vesicular glutamate and ATP from cultured rat astrocytes. Glia 40, 312-323. doi: 10.1002/glia.10124

Benfenati, V., Amiry-Moghaddam, M., Caprini, M., Mylonakou, M. N., Rapisarda, C., Ottersen, O. P., et al. (2007). Expression and functional characterization of transient receptor potential vanilloid-related channel 4 (TRPV4) in rat cortical astrocytes. Neuroscience 148, 876-892. doi: 10.1016/j.neuroscience.2007.06.039

Bolotina, V. M., Najibi, S., Palacino, J. J., Pagano, P. J., and Cohen, R. A. (1994). Nitric oxide directly activates calcium-dependent potassium channels in vascular smooth muscle. Nature 368, 850-853. doi: 10.1038/368850a0

Brožičková, C., and Otáhal, J. (2013). Effect of an inhibitor of neuronal nitric oxide synthase 7-nitroindazole on cerebral hemodynamic response and brain excitability in urethane-anesthetized rats. Physiol. Res. 62(Suppl. 1), S57-S66.

Bruzzone, S., Guida, L., Zocchi, E., Franco, L., and De Flora, A. (2001). Connexin 43 hemichannels mediate $\mathrm{Ca}^{2+}$-regulated transmembrane $\mathrm{NAD}^{+}$fluxes in intact cells. FASEB J. 15, 10-12. doi: 10.1096/fj.00-0566fje

Bruzzone, R., Hormuzdi, S. G., Barbe, M. T., Herb, A., and Monyer, H. (2003). Pannexins, a family of gap junction proteins expressed in brain. Proc. Natl. Acad. Sci. US A 100, 13644-13649. doi: 10.1073/pnas.2233464100

Buskila, Y., Abu-Ghanem, Y., Levi, Y., Moran, A., Grauer, E., and Amitai, Y. (2007). Enhanced astrocytic nitric oxide production and neuronal modifications in the neocortex of a NOS2 mutant mouse. PLoS One 2:e843. doi: 10.1371/journal. pone. 0000843

Chandrasekhar, A., and Bera, A. K. (2012). Hemichannels: permeants and their effect on development, physiology and death. Cell Biochem. Funct. 30, 89-100. doi: $10.1002 / \mathrm{cbf} .2794$

Cherian, P. P., Siller-Jackson, A. J., Gu, S., Wang, X., Bonewald, L. F., Sprague, E., et al. (2005). Mechanical strain opens connexin 43 hemichannels in osteocytes: a novel mechanism for the release of prostaglandin. Mol. Biol. Cell 16, 3100-3106. doi: 10.1091/mbc.e04-10-0912

De Bock, M., Culot, M., Wang, N., Bol, M., Decrock, E., De Vuyst, E., et al. (2011). Connexin channels provide a target to manipulate brain endothelial calcium dynamics and blood-brain barrier permeability. J. Cereb. Blood Flow Metab. 31, 1942-1957. doi: 10.1038/jcbfm.2011.86

De Bock, M., Wang, N., Bol, M., Decrock, E., Ponsaerts, R., Bultynck, G., et al. (2012). Connexin 43 hemichannels contribute to cytoplasmic $\mathrm{Ca}^{2+}$ oscillations by providing a bimodal $\mathrm{Ca}^{2+}$-dependent $\mathrm{Ca}^{2+}$ entry pathway. J. Biol. Chem. 287, 12250-12266. doi: 10.1074/jbc.M111.299610

Doyle, C. A., and Slater, P. (1997). Localization of neuronal and endothelial nitric oxide synthase isoforms in human hippocampus. Neuroscience 76, 387-395. doi: 10.1016/s0306-4522(96)00297-7

Dunn, K. M., Hill-Eubanks, D. C., Liedtke, W. B., and Nelson, M. T. (2013). TRPV4 channels stimulate $\mathrm{Ca}^{2+}$-induced $\mathrm{Ca}^{2+}$ release in astrocytic endfeet and amplify neurovascular coupling responses. Proc. Natl. Acad. Sci. U S A 110, 6157-6162. doi: 10.1073/pnas.1216514110

Evans, W. H., and Martin, P. E. (2002). Gap junctions: structure and function (Review). Mol. Membr. Biol. 19, 121-136. doi: 10.1080/0968768021 0139839

Ezan, P., André, P., Cisternino, S., Saubaméa, B., Boulay, A. C., Doutremer, S., et al. (2012). Deletion of astroglial connexins weakens the blood-brain barrier. J. Cereb. Blood Flow Metab. 32, 1457-1467. doi: 10.1038/jcbfm.2012.45

Fields, R. D., and Burnstock, G. (2006). Purinergic signalling in neuron-glia interactions. Nat. Rev. Neurosci. 7, 423-436. doi: 10.1038/nrn1928

Figueroa, X. F., Lillo, M. A., Gaete, P. S., Riquelme, M. A., and Sáez, J. C. (2013). Diffusion of nitric oxide across cell membranes of the vascular wall requires specific connexin-based channels. Neuropharmacology 75, 471-478. doi: 10. 1016/j.neuropharm.2013.02.022

Filosa, J. A., Bonev, A. D., and Nelson, M. T. (2004). Calcium dynamics in cortical astrocytes and arterioles during neurovascular coupling. Circ. Res. 95, e73-e81. doi: 10.1161/01.res.0000148636.60732.2e

Filosa, J. A., Bonev, A. D., Straub, S. V., Meredith, A. L., Wilkerson, M. K., Aldrich, R. W., et al. (2006). Local potassium signaling couples neuronal activity to vasodilation in the brain. Nat. Neurosci. 9, 1397-1403. doi: 10.1038/nn1779

Filosa, J. A., and Iddings, J. A. (2013). Astrocyte regulation of cerebral vascular tone. Am. J. Physiol. Heart Circ. Physiol. 305, H609-H619. doi: 10.1152/ajpheart. 00359.2013

Gabbott, P. L., and Bacon, S. J. (1996). Localisation of NADPH diaphorase activity and NOS immunoreactivity in astroglia in normal adult rat brain. Brain Res. 714, 135-144. doi: 10.1016/0006-8993(95)01509-4

Gaete, P. S., Lillo, M. A., and Figueroa, X. F. (2014). Functional role of connexins and pannexins in the interaction between vascular and nervous system. J. Cell. Physiol. 229, 1336-1345. doi: 10.1002/jcp.24563

Girouard, H., Bonev, A. D., Hannah, R. M., Meredith, A., Aldrich, R. W., and Nelson, M. T. (2010). Astrocytic endfoot $\mathrm{Ca}^{2+}$ and BK channels determine both 
arteriolar dilation and constriction. Proc. Natl. Acad. Sci. US A 107, 3811-3816. doi: 10.1073/pnas.0914722107

Golovina, V. A., and Blaustein, M. P. (1997). Spatially and functionally distinct $\mathrm{Ca}^{2+}$ stores in sarcoplasmic and endoplasmic reticulum. Science 275, 1643-1648. doi: 10.1126/science.275.5306.1643

Golovina, V. A., and Blaustein, M. P. (2000). Unloading and refilling of two classes of spatially resolved endoplasmic reticulum $\mathrm{Ca}(2+)$ stores in astrocytes. Glia 31, 15-28. doi: 10.1002/(sici) 1098-1136(200007)31:1<15::aid-glia20>3.0.co;2-h

Goodenough, D. A., and Paul, D. L. (2003). Beyond the gap: functions of unpaired connexon channels. Nat. Rev. Mol. Cell Biol. 4, 285-294. doi: 10.1038/ nrm1072

Gordon, G. R., Choi, H. B., Rungta, R. L., Ellis-Davies, G. C., and MacVicar, B. A. (2008). Brain metabolism dictates the polarity of astrocyte control over arterioles. Nature 456, 745-749. doi: 10.1038/nature07525

Hawkins, B. T., and Davis, T. P. (2005). The blood-brain barrier/neurovascular unit in health and disease. Pharmacol. Rev. 57, 173-185. doi: 10.1124/pr.57.2.4

Haydon, P. G., and Carmignoto, G. (2006). Astrocyte control of synaptic transmission and neurovascular coupling. Physiol. Rev. 86, 1009-1031. doi: 10. 1152/physrev.00049.2005

Iadecola, C. (2004). Neurovascular regulation in the normal brain and in Alzheimer's disease. Nat. Rev. Neurosci. 5, 347-360. doi: 10.1038/nrn1387

Ida, T., Hara, M., Nakamura, Y., Kozaki, S., Tsunoda, S., and Ihara, H. (2008). Cytokine-induced enhancement of calcium-dependent glutamate release from astrocytes mediated by nitric oxide. Neurosci. Lett. 432, 232-236. doi: 10.1016/j. neulet.2007.12.047

Iglesias, R., Dahl, G., Qiu, F., Spray, D. C., and Scemes, E. (2009). Pannexin 1: the molecular substrate of astrocyte "hemichannels". J. Neurosci. 29, 7092-7097. doi: 10.1523/JNEUROSCI.6062-08.2009

Isakson, B. E., Ramos, S. I., and Duling, B. R. (2007). $\mathrm{Ca}^{2+}$ and inositol 1,4,5trisphosphate-mediated signaling across the myoendothelial junction. Circ. Res. 100, 246-254. doi: 10.1161/01.res.0000257744.23795.93

Iwase, K., Iyama, K., Akagi, K., Yano, S., Fukunaga, K., Miyamoto, E., et al. (1998). Precise distribution of neuronal nitric oxide synthase mRNA in the rat brain revealed by non-radioisotopic in situ hybridization. Brain Res. Mol. Brain Res. 53, 1-12. doi: 10.1016/s0169-328x(97)00139-3

Jiménez, A. I., Castro, E., Mirabet, M., Franco, R., Delicado, E. G., and Miras-Portugal, M. T. (1999). Potentiation of ATP calcium responses by $\mathrm{A}_{2 \mathrm{~B}}$ receptor stimulation and other signals coupled to Gs proteins in type-1 cerebellar astrocytes. Glia 26, 119-128. doi: 10.1002/(sici)10981136(199904)26:2<119::aid-glia3>3.0.co;2-d

Joseph, S. M., Buchakjian, M. R., and Dubyak, G. R. (2003). Colocalization of ATP release sites and ecto-ATPase activity at the extracellular surface of human astrocytes. J. Biol. Chem. 278, 23331-23342. doi: 10.1074/jbc.m302680200

Kang, J., Kang, N., Lovatt, D., Torres, A., Zhao, Z., Lin, J., et al. (2008). Connexin 43 hemichannels are permeable to ATP. J. Neurosci. 28, 4702-4711. doi: 10. 1523/JNEUROSCI.5048-07.2008

Karagiannis, A., Gallopin, T., David, C., Battaglia, D., Geoffroy, H., Rossier, J., et al. (2009). Classification of NPY-expressing neocortical interneurons. J. Neurosci. 29, 3642-3659. doi: 10.1523/JNEUROSCI.0058-09.2009

Kitaura, H., Uozumi, N., Tohmi, M., Yamazaki, M., Sakimura, K., Kudoh, M., et al. (2007). Roles of nitric oxide as a vasodilator in neurovascular coupling of mouse somatosensory cortex. Neurosci. Res. 59, 160-171. doi: 10.1016/j.neures.2007.06. 1469

Koehler, R. C., Gebremedhin, D., and Harder, D. R. (2006). Role of astrocytes in cerebrovascular regulation. J. Appl. Physiol. (1985) 100, 307-317. doi: 10. 1152/japplphysiol.00938.2005

Lee, E. J., Shin, S. H., Hyun, S., Chun, J., and Kang, S. S. (2011). Mutation of a putative S-nitrosylation site of TRPV4 protein facilitates the channel activates. Animal Cells Syst. (Seoul) 15, 95-106. doi: 10.1080/19768354.2011.555183

Leybaert, L. (2005). Neurobarrier coupling in the brain: a partner of neurovascular and neurometabolic coupling? J. Cereb. Blood Flow Metab. 25, 2-16. doi: 10. 1038/si.jcbfm. 9600001

Li, N., Sul, J. Y., and Haydon, P. G. (2003). A calcium-induced calcium influx factor, nitric oxide, modulates the refilling of calcium stores in astrocytes. J. Neurosci. 23, 10302-10310.

Lin, L. H., Taktakishvili, O., and Talman, W. T. (2007). Identification and localization of cell types that express endothelial and neuronal nitric oxide synthase in the rat nucleus tractus solitarii. Brain Res. 1171, 42-51. doi: 10. 1016/j.brainres.2007.07.057
Lohman, A. W., Weaver, J. L., Billaud, M., Sandilos, J. K., Griffiths, R., Straub, A. C., et al. (2012). S-nitrosylation inhibits pannexin 1 channel function. J. Biol. Chem. 287, 39602-39612. doi: 10.1074/jbc.M112.397976

Martínez-Ruiz, A., Araújo, I. M., Izquierdo-Álvarez, A., Hernansanz-Agustín, P., Lamas, S., and Serrador, J. M. (2013). Specificity in S-nitrosylation: a shortrange mechanism for NO signaling? Antioxid. Redox Signal. 19, 1220-1235. doi: 10.1089/ars.2012.5066

Meno, J. R., Crum, A. V., and Winn, H. R. (2001). Effect of adenosine receptor blockade on pial arteriolar dilation during sciatic nerve stimulation. Am. J. Physiol. Heart Circ. Physiol. 281, H2018-H2027.

Metea, M. R., and Newman, E. A. (2006). Glial cells dilate and constrict blood vessels: a mechanism of neurovascular coupling. J. Neurosci. 26, 2862-2870. doi: 10.1523/jneurosci.4048-05.2006

Moncada, S., Palmer, R. M., and Higgs, E. A. (1991). Nitric oxide: physiology, pathophysiology and pharmacology. Pharmacol. Rev. 43, 109-142.

Mulligan, S. J., and MacVicar, B. A. (2004). Calcium transients in astrocyte endfeet cause cerebrovascular constrictions. Nature 431, 195-199. doi: 10. 1038/nature02827

Muoio, V., Persson, P. B., and Sendeski, M. M. (2014). The neurovascular unitconcept review. Acta Physiol. (Oxf.) 210, 790-798. doi: 10.1111/apha.12250

Ngai, A. C., Coyne, E. F., Meno, J. R., West, G. A., and Winn, H. R. (2001). Receptor subtypes mediating adenosine-induced dilation of cerebral arterioles. Am. J. Physiol. Heart Circ. Physiol. 280, H2329-H2335.

Nilius, B., and Voets, T. (2005). TRP channels: a TR(I)P through a world of multifunctional cation channels. Pflugers Arch. 451, 1-10. doi: 10.1007/s00424005-1462-y

Orellana, J. A., Figueroa, X. F., Sánchez, H. A., Contreras-Duarte, S., Velarde, V., and Sáez, J. C. (2011). Hemichannels in the neurovascular unit and white matter under normal and inflamed conditions. CNS Neurol. Disord. Drug Targets 10, 404-414. doi: 10.2174/187152711794653869

Panchin, Y., Kelmanson, I., Matz, M., Lukyanov, K., Usman, N., and Lukyanov, S. (2000). A ubiquitous family of putative gap junction molecules. Curr. Biol. 10, R473-R474. doi: 10.1016/s0960-9822(00)00576-5

Parri, H. R., and Crunelli, V. (2003). The role of $\mathrm{Ca}^{2+}$ in the generation of spontaneous astrocytic $\mathrm{Ca}^{2+}$ oscillations. Neuroscience 120, 979-992. doi: 10. 1016/s0306-4522(03)00379-8

Pautz, A., Art, J., Hahn, S., Nowag, S., Voss, C., and Kleinert, H. (2010). Regulation of the expression of inducible nitric oxide synthase. Nitric Oxide 23, 75-93. doi: 10.1016/j.niox.2010.04.007

Pedersen, S. F., Owsianik, G., and Nilius, B. (2005). TRP channels: an overview. Cell Calcium 38, 233-252. doi: 10.1016/j.ceca.2005.06.028

Pelligrino, D. A., Vetri, F., and Xu, H. L. (2011). Purinergic mechanisms in gliovascular coupling. Semin. Cell Dev. Biol. 22, 229-236. doi: 10.1016/j.semcdb. 2011.02.010

Perkins, G. A., Goodenough, D. A., and Sosinsky, G. E. (1998). Formation of the gap junction intercellular channel requires a 30 degree rotation for interdigitating two apposing connexons. J. Mol. Biol. 277, 171-177. doi: 10.1006/jmbi.1997. 1580

Pilitsis, J. G., and Kimelberg, H. K. (1998). Adenosine receptor mediated stimulation of intracellular calcium in acutely isolated astrocytes. Brain Res. 798, 294-303. doi: 10.1016/s0006-8993(98)00430-2

Porter, J. T., and McCarthy, K. D. (1997). Astrocytic neurotransmitter receptors in situ and in vivo. Prog. Neurobiol. 51, 439-455. doi: 10.1016/s03010082(96)00068-8

Price, D. L., Ludwig, J. W., Mi, H., Schwarz, T. L., and Ellisman, M. H. (2002). Distribution of rSlo $\mathrm{Ca}^{2+}$-activated $\mathrm{K}^{+}$channels in rat astrocyte perivascular endfeet. Brain Res. 956, 183-193. doi: 10.1016/s0006-8993(02)03266-3

Pryazhnikov, E., and Khiroug, L. (2008). Sub-micromolar increase in $[\mathrm{Ca}(2+)](\mathrm{i})$ triggers delayed exocytosis of ATP in cultured astrocytes. Glia 56, 38-49. doi: 10. 1002/glia.20590

Retamal, M. A., Cortés, C. J., Reuss, L., Bennett, M. V., and Sáez, J. C. (2006). Snitrosylation and permeation through connexin 43 hemichannels in astrocytes: induction by oxidant stress and reversal by reducing agents. Proc. Natl. Acad. Sci. U S A 103, 4475-4480. doi: 10.1073/pnas.0511118103

Rolfe, D. F., and Brown, G. C. (1997). Cellular energy utilization and molecular origin of standard metabolic rate in mammals. Physiol. Rev. 77, 731-758.

Saez, J. C., Berthoud, V. M., Branes, M. C., Martinez, A. D., and Beyer, E. C. (2003). Plasma membrane channels formed by connexins: their regulation and functions. Physiol. Rev. 83, 1359-1400. doi: 10.1152/physrev.00007.2003 
Schipke, C. G., Heidemann, A., Skupin, A., Peters, O., Falcke, M., and Kettenmann, H. (2008). Temperature and nitric oxide control spontaneous calcium transients in astrocytes. Cell Calcium 43, 285-295. doi: 10.1016/j.ceca.2007.06.002

Sengupta, R., and Holmgren, A. (2013). Thioredoxin and thioredoxin reductase in relation to reversible S-nitrosylation. Antioxid. Redox Signal. 18, 259-269. doi: 10.1089/ars.2012.4716

Shi, Y., Liu, X., Gebremedhin, D., Falck, J. R., Harder, D. R., and Koehler, R. C. (2008). Interaction of mechanisms involving epoxyeicosatrienoic acids, adenosine receptors and metabotropic glutamate receptors in neurovascular coupling in rat whisker barrel cortex. J. Cereb. Blood Flow Metab. 28, 111-125. doi: $10.1038 /$ sj.jcbfm. 9600511

Shin, T. (2001). Increased expression of neuronal nitric oxide synthase in astrocytes and macrophages in the spinal cord of Lewis rats with autoimmune encephalomyelitis. J. Vet. Sci. 2, 195-199. doi: 10.1016/j.brainres.2012. 03.023

Simard, M., Arcuino, G., Takano, T., Liu, Q. S., and Nedergaard, M. (2003). Signaling at the gliovascular interface. J. Neurosci. 23, 9254-9262.

Sipos, A., Vargas, S. L., Toma, I., Hanner, F., Willecke, K., and Peti-Peterdi, J. (2009). Connexin 30 deficiency impairs renal tubular ATP release and pressure natriuresis. J. Am. Soc. Nephrol. 20, 1724-1732. doi: 10.1681/ASN.2008101099

Stobart, J. L., Lu, L., Anderson, H. D., Mori, H., and Anderson, C. M. (2013). Astrocyte-induced cortical vasodilation is mediated by D-serine and endothelial nitric oxide synthase. Proc. Natl. Acad. Sci. U S A 110, 3149-3154. doi: 10. 1073/pnas. 1215929110

Stout, C. E., Costantin, J. L., Naus, C. C., and Charles, A. C. (2002). Intercellular calcium signaling in astrocytes via ATP release through connexin hemichannels. J. Biol. Chem. 277, 10482-10488. doi: 10.1074/jbc.m109902200

Straub, S. V., Bonev, A. D., Wilkerson, M. K., and Nelson, M. T. (2006). Dynamic inositol trisphosphate-mediated calcium signals within astrocytic endfeet underlie vasodilation of cerebral arterioles. J. Gen. Physiol. 128, 659-669. doi: 10.1085/jgp.200609650

Straub, S. V., and Nelson, M. T. (2007). Astrocytic calcium signaling: the information currency coupling neuronal activity to the cerebral microcirculation. Trends Cardiovasc. Med. 17, 183-190. doi: 10.1016/j. tcm.2007.05.001

Suadicani, S. O., Iglesias, R., Spray, D. C., and Scemes, E. (2009). Point mutation in the mouse $\mathrm{P}_{2} \mathrm{X}_{7}$ receptor affects intercellular calcium waves in astrocytes. ASN Neuro 1:e00005. doi: 10.1042/AN20090001

Suadicani, S. O., Iglesias, R., Wang, J., Dahl, G., Spray, D. C., and Scemes, E. (2012). ATP signaling is deficient in cultured Pannexin1-null mouse astrocytes. Glia 60, 1106-1116. doi: 10.1002/glia.22338

Svenningsen, P., Burford, J. L., and Peti-Peterdi, J. (2013). ATP releasing connexin 30 hemichannels mediate flow-induced calcium signaling in the collecting duct. Front. Physiol. 4:292. doi: 10.3389/fphys.2013.00292

Takano, T., Tian, G. F., Peng, W., Lou, N., Libionka, W., Han, X., et al. (2006). Astrocyte-mediated control of cerebral blood flow. Nat. Neurosci. 9, 260-267. doi: $10.1038 / \mathrm{nn} 1623$

Tanaka, Y., Igarashi, T., Kaneko, H., Yamaki, F., Mochizuki, Y., Aida, M., et al. (2000). NO-mediated MaxiK(Ca) channel activation produces relaxation of guinea pig aorta independently of voltage-dependent L-type $\mathrm{Ca}(2+)$ channels. Gen. Pharmacol. 34, 159-165. doi: 10.1016/s0306-3623(00)00056-2
Tang, Q., Dowd, T. L., Verselis, V. K., and Bargiello, T. A. (2009). Conformational changes in a pore-forming region underlie voltage-dependent "loop gating" of an unapposed connexin hemichannel. J. Gen. Physiol. 133, 555-570. doi: 10. 1085/jgp.200910207

Tao, L., and Harris, A. L. (2007). 2-aminoethoxydiphenyl borate directly inhibits channels composed of connexin26 and/or connexin32. Mol. Pharmacol. 71, 570-579. doi: 10.1124/mol.106.027508

Thompson, R. J., and MacVicar, B. A. (2008). Connexin and pannexin hemichannels of neurons and astrocytes. Channels (Austin) 2, 81-86. doi: 10 . 4161/chan.2.2.6003

Tricoire, L., Pelkey, K. A., Daw, M. I., Sousa, V. H., Miyoshi, G., Jeffries, B., et al. (2010). Common origins of hippocampal Ivy and nitric oxide synthase expressing neurogliaform cells. J. Neurosci. 30, 2165-2176. doi: 10. 1523/JNEUROSCI.5123-09.2010

Unger, V. M., Kumar, N. M., Gilula, N. B., and Yeager, M. (1999). Threedimensional structure of a recombinant gap junction membrane channel. Science 283, 1176-1180. doi: 10.1126/science.283.5405.1176

Vetri, F., Xu, H., Mao, L., Paisansathan, C., and Pelligrino, D. A. (2011). ATP hydrolysis pathways and their contributions to pial arteriolar dilation in rats. Am. J. Physiol. Heart Circ. Physiol. 301, H1369-H1377. doi: 10.1152/ajpheart. 00556.2011

Xu, H. L., and Pelligrino, D. A. (2007). ATP release and hydrolysis contribute to rat pial arteriolar dilatation elicited by neuronal activation. Exp. Physiol. 92, 647-651. doi: 10.1113/expphysiol.2006.036863

Zhang, L., Deng, T., Sun, Y., Liu, K., Yang, Y., and Zheng, X. (2008). Role for nitric oxide in permeability of hippocampal neuronal hemichannels during oxygen glucose deprivation. J. Neurosci. Res. 86, 2281-2291. doi: 10.1002/jnr.21675

Zonta, M., Angulo, M. C., Gobbo, S., Rosengarten, B., Hossmann, K. A., Pozzan, T., et al. (2003a). Neuron-to-astrocyte signaling is central to the dynamic control of brain microcirculation. Nat. Neurosci. 6, 43-50. doi: 10.1038/nn980

Zonta, M., Sebelin, A., Gobbo, S., Fellin, T., Pozzan, T., and Carmignoto, G. (2003b). Glutamate-mediated cytosolic calcium oscillations regulate a pulsatile prostaglandin release from cultured rat astrocytes. J. Physiol. 553, 407-414. doi: 10.1113/jphysiol.2003.046706

Conflict of Interest Statement: The authors declare that the research was conducted in the absence of any commercial or financial relationships that could be construed as a potential conflict of interest.

Received: 01 December 2014; accepted: 07 February 2015; published online: 10 March 2015.

Citation: Muñoz MF, Puebla M and Figueroa XF (2015) Control of the neurovascular coupling by nitric oxide-dependent regulation of astrocytic $\mathrm{Ca}^{2+}$ signaling. Front. Cell. Neurosci. 9:59. doi: 10.3389/fncel.2015.00059

This article was submitted to the journal Frontiers in Cellular Neuroscience.

Copyright (c) 2015 Muñoz, Puebla and Figueroa. This is an open-access article distributed under the terms of the Creative Commons Attribution License (CC BY). The use, distribution and reproduction in other forums is permitted, provided the original author(s) or licensor are credited and that the original publication in this journal is cited, in accordance with accepted academic practice. No use, distribution or reproduction is permitted which does not comply with these terms. 